\title{
All Things are Lawful, but not all Things are Helpful. Reflections on the Risk Factors in Cardiovascular Disease
}

\author{
Sur Genel ${ }^{1,2^{*}}$, Floca Emanuela ${ }^{1}$, Sur Daniel $\mathbf{G}^{1}$, Miclos M Corina ${ }^{1}$ and Sur M Lucia ${ }^{1}$ \\ ${ }^{1}$ University of Medicine and Pharmacy, Iuliu Hatieganu, Romania \\ ${ }^{2}$ Emergency Clinical Hospital for Children, Romania
}

"Corresponding author: Sur Genel, University of Medicine and Pharmacy, luliu Hatieganu, Cluj-Napoca, Romania, Tel: 0724504964; E-mail: surgenel@yahoo.com Rec date: May 26, 2014, Acc date: June 01, 2014, Pub date: June 06, 2014

Copyright: (c) 2014 Genel S, et al. This is an open-access article distributed under the terms of the Creative Commons Attribution License, which permits unrestricted use, distribution, and reproduction in any medium, provided the original author and source are credited

\begin{abstract}
Based on the results of personal research authors looked to see which risk factors can be influenced in hypertension determinism. It is known that the genetic factor is present in $20-40 \%$ of patients. But this genetic factor does not validate unless, other factors interfere to allow the occurrence of hypertension. The factors which can be influenced significantly are those related to the individual's lifestyle. The lifestyle can accelerate the occurrence of hypertension or on the contrary stop the development of hypertension. Factors that can be influenced are: consumption of salt, consumption of fatty foods, alcohol, smoking and sedentary behavior. To influence the real prevalence of hypertension prevention measures should start in childhood. People should act on the principle "it is easier to prevent than to treat". At the same time this principle is beneficial both economically and individually. Unfortunately, most studies use persons in older age, so the comorbidities are more frequent and the cardiovascular complications occurred already. In future will be diagnosed young people at risk of developing hypertension and monitored to lead a normal life.
\end{abstract}

Keywords: Hypertension; Risk factors; Lifestyle

\section{Introduction}

At the end of 2002 WHO developed a very comprehensive report on the health of the world; on this project collaborated experts from around the world. This was the most extensive analysis undertaken in health. The report aims to eliminate risks and promote a healthy lifestyle. Were identified 10 risk factors worldwide, and of those, the top positions are occupied by hypertension, obesity and hypercholesterolemia. The report highlighted the causes of disease and causes of death, but also the human habits and their evolution in the contemporary world. A disturbing fact revealed by the report shows that, $75 \%$ of all cardiovascular diseases risk factors are: obesity, hypertension, hypercholesterolemia, sedentary behaviour and smoking. These risk factors could be eliminated by changes in daily habits, but these people should realize the necessity of a proper lifestyle $[1,2]$.

The WHO report shows that many people live dangerously and that individuals in developed countries have moved on to a wrong lifestyle. Tobacco and alcohol have increasingly penetrated in underdeveloped countries, coloring lifestyle of individuals, but at the same time being a risk factor. In future, efforts will be made for people to realize that, it is easier to prevent than to treat, and health costs are infinitely more acceptable. The health policies will be promoting health programs to stop or eliminate risk factors. According to Paul prediction "all things are lawful, but not all things are helpful" (1 Corinthians 10:23 ESV), the individuals should understand that from the multitude of culinary pleasures offered, they should choose those that will not affect their health [3].

\section{Epidemiology}

It is estimated that $20 \%$ of the adult population of the globe shows hypertension. Frequency increases significantly with age, reaching $50 \%$ in patients over 60 years [1,2].

The WHO report from 2002 shows that about $11 \%$ of the global loads disease is caused by high blood pressure and more than $50 \%$ of coronary heart disease and $75 \%$ of strokes are due to increased systolic blood pressure above the theoretical minimum value of 115-120 mmHg [2].

An extensive study undertaken in Romania found a prevalence of hypertension in the general population of $40 \%$. A regional study undertaken by the author shows a prevalence of hypertension of $30 \%$.

Our study evaluated 2266 subjects. In our study there was an increased consumption of salt (over $10 \mathrm{~g} / 24$ hours) in hypertensive patients, representing $45.25 \%$ compared to $19.28 \%$ in the group of subjects without hypertension. In our study we found increased alcohol consumption (more than $40 \mathrm{~g}$ alcohol / day) in hypertensive patients representing $45.69 \%$ compared to $35 \%$ in the group of individuals without hypertension. There was a predominance of males in the consumption of alcohol. Of all hypertensive patients only $52.52 \%$ practiced daily physical activity, compared with $75.31 \%$ in individuals without hypertension. Regarding smoking in the hypertensive group, smokers and former smokers represent $43.18 \%$. Group of individuals without hypertension behave almost the same. Analyze the prevalence of obesity in patients with hypertension showed its presence in $47.18 \%$ of patient.

\section{Hypertension and Risk Factors}

Essential hypertension is defined as a persistent increase in systolic blood pressure and diastolic above 140/90 $\mathrm{mmHg}$. In the determinism of hypertension an important role is represented by genetic factor. Over time was proved that essential hypertension has a multifactorial etiology, being produced by several genes whose effect is modulated by the interaction between multiple genes and between gene and environment. Also the individual genetic factors are influenced by both environmental and lifestyle factors. It is estimated that the genetic factor has a share of $30-60 \%$ in the determinism of essential hypertension. It has been shown that if one parent has hypertension, the descendants' chances to develop hypertension are $20 \%$, and if both parents have hypertension descendants' chances are $40 \%$. If none of the parents have hypertension, descendants' chances are $3-4 \%[1,4]$. 
The main problem of heredity hypertension is the identification of multiple susceptibility genes and the effect of different allelic variants in modulating blood pressure. Some alleles of many genes are involved in the development of hypertension. They are commonly present in hypertensive than in normotensive individuals and must pass on with hypertension in the family. Gene selection was made according to the mechanisms and molecules involved in regulation of blood pressure. The key role is taken by the kidneys, adrenal glands, nervous system that participates in pressure-natriuresis mechanism controlled by the renin-angiotensin-aldosterone system. Have been identified and localized genes that encode the various components of the system: ADD1 gene (alpha-adducina, hydrostatic pressure sensor change), AGT gene (for angiotensinogen, which are significantly associated with hypertension), gene for rennin, ACE gene (angiotensin converting enzyme, located on chromosome 17q23), AT1R gene (angiotensin receptor), CYP11B2 gene (aldosterone synthase), SCNN1B gene (beta subunit of the sodium channel non-voltage-dependent type 1) [1,4].

Renal function impairment in relation to genetic factors leads to apparition of essential hypertension. Young patients coming from hypertensive parents has revealed increased plasma flow, glomerular filtration rate greater and increased glomerular resistance. It is assumed that familial predisposition to hypertension could be due to innate factors that disrupt renal sodium excretion, either by lower filtering of the kidney, either through a higher resorption at tubules level. In practice it was found (Guidi et al.) that the recipients of a kidney from a donor with hypertension have values of blood pressure higher than those who have donors without hypertension. We can say that blood pressure follows the kidneys. If you transplant a kidney from a normotensive patient to a hypertensive patient, its blood pressure become normal, but the phenomenon is also true vice versa [5].

The kidney plays a role in the pathogenesis of hypertension by two mechanisms: sodium excretion and renin secretion. There are two important assumptions about pathogenic mechanisms in hypertensive patients (with center in kidney): the kidney-volume-pressure adjusting mechanism (Guyton) and heterogeneity population of nephrons hypothesis (Saley).

Lifestyle includes factors that may influence the blood pressure. Those who have a family history of hypertension are at high risk for developing hypertension. In those who don't have family history, the lifestyle can contribute to the validation of comorbidities, such as obesity, dyslipidemia, diabetes mellitus, which can eventually lead to hypertension. Eating habits contribute significantly at the onset and maintenance of hypertension [3].

Increased salt consumption plays an important role in the development and maintenance of hypertension. We know that we consume more salt than we need, and excess salt intake increases volume expansion and simultaneously increases cellular receptor responsiveness to pressor substances action. Accumulation of sodium in the cell wall is genetically determined and occurs in $20-30 \%$ of patients with hypertension who eat more than $10 \mathrm{~g}$ salt $/ 24$ hours. Hypertensives respond differently to increased salt intake, which is explained by the transmembrane sodium excretion and transmembranar transport of sodium. Increased salt consumption remains a significant risk factor for hypertension, if it is correlated with genetic abnormalities in the transmembranar transport of sodium $[6,7]$.
Studies made on large groups of hypertensive patients have shown that reducing salt intake lowers blood pressure. The effects are more significant in patients older than 45 years. It was found that a third of hypertensives can normalize their blood pressure only by hygienicdietary regime and by reducing salt intake below $24 \mathrm{~g} / 24$ hours. This happens particularly in hypertensive individuals "salt sensitives" in which the low-salt diet and diuretics are very effective $[7,8]$.

Although alcohol has an immediate vasodepressor effect, by chronic consumption may increase blood pressure. This was due to alterations in cell membrane permeability (that allows more calcium to enter the cell), sympathetic stimulation, induction of insulin resistance with hyperinsulinemia and increased cortisol secretion. Increased alcohol consumption will increase cardiac output, heart rate, sympathetic activity and catecholamine secretion $[9,10]$.

In conditions in which are associated other factors such as drinking coffee, smoking, even small amounts of alcohol consumed chronically, can lead to high blood pressure.

Increased alcohol consumption influences individual behavior negatively making it vulnerable to hazards, including food. In hypertensive patients increased alcohol consumption can lead to cardiac complications by the mechanisms described above. In addition, alcohol also leads to discontinuation of antihypertensive treatment and ignorance of food hazards. Awareness of the necessity to reduce or eliminate alcohol consumption should be publicized since school age. There are unfortunately many advertisements promoting alcohol, without explaining the risks to which individuals are exposed. There are also many films and serials in which smoking and tobacco are always present.

Smoking has an acute hypertensive effect by stimulating the sympathetic nervous system. Smoking can cause or exacerbate hypertension by affecting arterial stiffness and wave reflection. Current data do not support a direct causal relationship between chronic smoking and hypertension. It was found that hypertensive smokers are more likely to develop severe forms of hypertension (renovascular and malignant hypertension) $[11,12]$.

Smoking is a major risk factor for cardiovascular diseases. Smoking, by impaired endothelial function, arterial stiffness, inflammation, lipid modification and alteratioan of antithrombotic and prothrombotic factor, causes initiation and acceleration of atherothrombotic process. Thus cigarette smoking leads to cardiovascular events [11,13].

Smoking is more common among young people and on the long term, this unhealthy habit can cause real health problems. Those who like smoking, have the tendency to ignore all the negative signals they receive. Promoting education in this sense since school can bring favorable results for the awareness of quitting smoking. State could intervene by banning smoking in all public places and in pubs and clubs.

A sedentary life can cause hypertension by favoring obesity, diabetes, atherosclerosis and HDL-cholesterol decreasing. People who make daily physical activity rarely develop hypertension than individuals with sedentary behavior. Hypertensive patients can decrease their blood pressure through daily physical exercise. Sedentary lifestyle predisposes to obesity, because individuals assimilate by eating more calories than consumed. In addition there are different culinary temptations, and by the large number of calories contained, invariably lead to obesity. Sedentary lifestyle leads to appearance of cardiovascular complications by adding more risk 
Citation: Genel S, Emanuela F, Daniel SG, Corina MM, Lucia SM (2014) All Things are Lawful, but not all Things are Helpful. Reflections on the Risk Factors in Cardiovascular Disease . J Diabetes Metab 5: e114. doi:10.4172/2155-6156.1000e114

Page 3 of 3

factors, it is therefore recommended to practice physical exercises at least 30 minutes each day. Technology induces inactivity by searching information on the internet that does not require high energy physics. Shortcomings could be corrected if sedentary individuals are aware of the need for exercise and daily movement. In this sense even walking at least $3 \mathrm{~km}$ per day is beneficial [14].

Obesity Lifestyle and eating habits have led to the progressive increase in the number of obese and overweight individuals. It is estimated that obesity (with BMI> $=40$ ) decreases life expectancy with 20 years for men and 5 years for women; in the same time obesity increases the risk of cardiovascular complications. This should lead to strict action, to stop the occurrence of obesity. You can prevent obesity by making the healthy lifestyle and healty eating habits accessible to all individuals. Obesity leads to high blood pressure and it is found that many hypertensives are obese [15].

The mechanisms by which obesity contributes to increased blood pressure are sympathetic nervous system activation, diuresis and natriuresis mechanism, renin activity, renin-angiotensin-aldosterone mechanism, insulin resistance and inflammation, leptin and other neuropeptides. Understanding the mechanisms of production of hypertension in obese patients has an important role in the treatment of hypertension $[16,17]$.

\section{References}

1. TheTask Force for the management ofarterial hypertension of the European Society ofHypertension (ESH) and of the European Society of Cardiology (ESC) (2013) $2013 \mathrm{ESH} / \mathrm{ESC}$ Guidelines for the management of arterial hypertension. J Hypertension 31: 1281-1357.

2. Meena S Madhur, David J Maron. Hypertension. http:// emedicine.medscape.com/article/241381-overview

3. Vasan RS (2009) A risk score for risk factors: rationale and roadmap for preventing hypertension. Hypertension 54: 454-456.

4. Ehret GB (2010) Genome-wide association studies: contribution of genomics to understanding blood pressure and essential hypertension. Curr Hypertens Rep 12: 17-25.
5. Mangray M, Vella JP (2011) Hypertension after kidney transplant. Am J Kidney Dis 57: 331-341.

6. Susic D, Frohlich ED (2012) Salt consumption and cardiovascular, renal, and hypertensive diseases: clinical and mechanistic aspects. Curr Opin Lipidol 23: 11-16.

7. Cornélio ME, Gallani MC, Godin G, Rodrigues RC, Nadruz W Jr, et al. (2012) Behavioural determinants of salt consumption among hypertensive individuals. J Hum Nutr Diet 25: 334-344.

8. Bibbins-Domingo K, Chertow GM, Coxson PG, Moran A, Lightwood JM, et al. (2010) Projected effect of dietary salt reductions on future cardiovascular disease. N Engl J Med 362: 590-599.

9. Hillbom M, Saloheimo P, Juvela S (2011) Alcohol consumption, blood pressure, and the risk of stroke. Curr Hypertens Rep 13: 208-213.

10. Parati G, Esler M (2012) The human sympathetic nervous system: its relevance in hypertension and heart failure. Eur Heart J 33: 1058-1066.

11. Virdis A, Giannarelli C, Neves MF, Taddei S, Ghiadoni L (2010) Cigarette smoking and hypertension. Curr Pharm Des 16: 2518-2525.

12. Hering D, Kucharska W, Kara T, Somers VK, Narkiewicz K (2010) Smoking is associated with chronic sympathetic activation in hypertension. Blood Press 19: 152-155.

13. Mitchell GF, Hwang SJ, Vasan RS, Larson MG, Pencina MJ, et al. (2010) Arterial stiffness and cardiovascular events: the Framingham Heart Study. Circulation 121: 505-511.

14. Mitchell GF, Hwang SJ, Vasan RS, Larson MG, Pencina MJ, et al. (2010) Arterial stiffness and cardiovascular events: the Framingham Heart Study. Circulation 121: 505-511.

15. Thorp AA, Owen N, Neuhaus M, Dunstan DW (2011) Sedentary behaviors and subsequent health outcomes in adults a systematic review of longitudinal studies, 1996-2011. Am J Prev Med 41: 207-215.

16. Re RN (2009) Obesity-related hypertension. Ochsner J 9: 133-136.

17. Hall JE, da Silva AA, do Carmo JM, Dubinion J, Hamza S, et al. (2010) Obesity-induced hypertension: role of sympathetic nervous system, leptin, and melanocortins. J Biol Chem 285: 17271-17276. 